\title{
Optimal valve location in long oil pipelines
}

\author{
Citation for published version (APA):
}

Grigoriev, A., \& Grigorieva, N. V. (2007). Optimal valve location in long oil pipelines. METEOR, Maastricht University School of Business and Economics. METEOR Research Memorandum No. 007 https://doi.org/10.26481/umamet.2007007

Document status and date:

Published: 01/01/2007

DOI:

10.26481/umamet.2007007

Document Version:

Publisher's PDF, also known as Version of record

\section{Please check the document version of this publication:}

- A submitted manuscript is the version of the article upon submission and before peer-review. There can be important differences between the submitted version and the official published version of record.

People interested in the research are advised to contact the author for the final version of the publication, or visit the DOI to the publisher's website.

- The final author version and the galley proof are versions of the publication after peer review.

- The final published version features the final layout of the paper including the volume, issue and page numbers.

Link to publication

\footnotetext{
General rights rights.

- You may freely distribute the URL identifying the publication in the public portal. please follow below link for the End User Agreement:

www.umlib.nl/taverne-license

Take down policy

If you believe that this document breaches copyright please contact us at:

repository@maastrichtuniversity.nl

providing details and we will investigate your claim.
}

Copyright and moral rights for the publications made accessible in the public portal are retained by the authors and/or other copyright owners and it is a condition of accessing publications that users recognise and abide by the legal requirements associated with these

- Users may download and print one copy of any publication from the public portal for the purpose of private study or research.

- You may not further distribute the material or use it for any profit-making activity or commercial gain

If the publication is distributed under the terms of Article $25 \mathrm{fa}$ of the Dutch Copyright Act, indicated by the "Taverne" license above, 
N.V. Grigorieva, A. Grigoriev

Optimal valve location in long oil pipelines

$\mathrm{RM} / 07 / 007$

\section{METE@R}

Maastricht research school of Economics of TEchnology and ORganizations

Universiteit Maastricht

Faculty of Economics and Business Administration P.O. Box 616

NL - 6200 MD Maastricht

phone : :+31 433883830

fax : $\quad++31433884873$ 



\title{
Optimal valve location in long oil pipelines
}

\author{
Nadejda V. Grigorieva ${ }^{1}$ and Alexander Grigoriev ${ }^{2}$ \\ 1 Institute of Power Resources Transport (IPTER) \\ $144 / 3$, pr. Octyabrya, Ufa-450055, Russia \\ ipter@anrb.ru \\ 2 Maastricht University, Faculty of Economics and Business Administration, \\ Quantitative Economics, P.O. Box 616, 6200 MD Maastricht, The Netherlands \\ a.grigoriev@ke.unimaas.nl
}

\begin{abstract}
We address the valve location problem, one of the basic problems in design of long oil pipelines. Whenever a pipeline is depressurized, the shutoff valves block the oil flow and seal the damaged part of the pipeline. Thus, the quantity of oil possibly contaminating the area around the pipeline is determined by the volume of the damaged section of the pipeline between two consecutive valves. Then, ecologic damage can be quantified by the amount of leaked oil and the environmental characteristics of the accident area. Given a pipe network together with environmental characteristics of the area, and given a number of valves to be installed, the task is to find a valve location minimizing the maximal possible environmental damage. In this paper we present a complete framework for fast computing of an optimal valve location.
\end{abstract}

Keywords: Industries: Petroleum-natural gas; Transportation; Environment, Pollution; Reliability: System safety; Dynamic programming, Applications.

\section{Introduction and motivation}

A pipeline is the most efficient way to transport large quantities of crude oil over land. Compared to the railroad transportation, it has much lower per unit cost and much higher capacity. For instance, the world's longest oil pipeline "Druzhba" carries oil some 4000 kilometers from Siberia to the destination points in Western Europe with a daily capacity of 190 thousand tons. Not only economically efficient, a pipeline is also the most environmentally friendly way of oil transportation. The pipes are usually made of 16 millimeter 
thick steel and integrity of the pipelines is provided by a variety of high-tech solutions. Thus, when operating normally, pipelines do not produce any pollution. However, due to external factors or pipe corrosion, accidents on pipelines sometimes happen. Though the risk of an accident is very moderate, the environmental damage can be substantial. This is amplified by the fact that the pipelines are usually the primary targets for vandalism, sabotage, or even terrorist attacks.

Problem description. To control possible spills, every long oil pipeline is equipped with special shutoff valves which can quickly separate a damaged section of the pipeline. Whenever the pipeline is depressurized (oil is leaking), the valves automatically seal the pipeline separating it into sections. Therefore, the quantity of oil potentially leaving the pipeline system is limited to the volume of the damaged section of the pipeline between two consecutive valves. Then, the ecologic damage can be quantified by the amount of leaked oil and the environmental characteristics of the accident area, e.g. landscape, presence of rivers, lakes, swamps, inhabited localities, roads etc. Given a pipeline network together with environmental characteristics of the area around it, and a number of valves to be installed, the problem is to find a valve location that minimizes the maximal possible environmental damage. We refer to this problem as the valve location problem.

The valve location problem as a part of decision making process. In pipeline design, there are two basic problems. The first one is to choose a pipeline route and the second one is to locate along this route complex control devices like valves, tanks, pump stations, etc. To find the most economically efficient and environmentally friendly solution for a pipeline, a lot of simulations take place, where thousands routes are being considered, and for each of these routes the valve location problem should be solved to optimality. Therefore, one of the basic requirements to the methods solving the valve location problem is that optimal valve locations have to be computed very quickly (almost instantly) even for very large instances of the problem. 
Current approaches and recent developments. Currently, the valve location methods are quite straightforward. In Russia, for instance, the standard criteria for the valve location is minimization of the average amount of potentially leaked oil. In particular, this means that on a relatively plain landscape the valves will be installed equidistant from each other independent on any local specifics. According to this methodology, introduced in early seventieth by the Russian State Scientific Research Institute of Oil Transportation (1972), the only hard constraint coming from environmental concerns is that the distance between two consecutive valves cannot exceed 30 kilometers. Clearly, with the same amount of leaking oil, the environmental damage in desert, mountains, grassland or riverland will be very much different, and therefore, must be treated accordingly. Actually, in case of an accident, the above mentioned valve location minimizes the loss of the oil transporting company rather then environmental damage (though the primal predestination of shutoff valves is to provide ecologic safety of pipelines).

In 2002, US Department of Transportation (DOT) asked National Association of Pipeline Safety Representatives (NAPSR) to review the hazardous liquid pipeline safety standards; for a complete list of NAPSR recommendations and DOT responses see Federal Register (2002). We cite from this document the part concerning NAPSR recommendation on the valve location: "Establish a 10-mile maximum distance between shutoff valves to minimize the adverse effects of spills". In the DOT response we find that there was insufficient justification to require the installation of valves at uniform intervals. Moreover, in the new regulation, DOT explicitly allows variations in the inter-valve distances establishing the clear objective: "A valve must be installed on each mainline at locations along the pipeline system that will minimize damage or pollution from accidental hazardous liquid discharge, as appropriate for the terrain in open country, for offshore areas, or for populated areas"; see Electronic Code of Federal Regulations (2007). The present paper introduces the first complete decision making framework to achieve the stated objective.

In 2004-2005, several international environmental organizations have also addressed the issues of differentiating approaches to pipeline 
construction according to sensitivity of the pipeline areas. A good example of such environmental concerns is the recent discussion on the route of Eastern Siberia - Pacific Ocean oil pipeline (ESPO); see Greenpeace (2005). This 4130 kilometers long pipeline will export Russian crude oil to the Asia-Pacific markets in Japan, China and Korea. On the way of this pipeline there is lake Baikal which is a unique and extremely sensitive natural area. To protect this high consequence area, the pipeline route will be moved 40 kilometers north of Baikal instead of originally planned 800 meters. Moreover, Russian oil transport operator TRANSNEFT suggested extraordinary short inter-valve distances of 15 kilometers. In this paper we show that even with such short distances between the valves, the ecologic damage can vary a lot depending on the valve location solution. Thus, we propose a technique for computing the optimal valve location. We show that, with the same number of shutoff valves, solutions provided by our framework allow to reduce the ecologic damage up to $40 \%$ compared to the currently used valve location solutions.

Our results. First of all, we present a complete framework for computing an optimal valve location that explicitly takes into account environmental characteristics of the pipeline area. Secondly, the underlying algorithms are fast enough to solve large real-life instances within seconds even on medium quality personal computers. Thirdly, our methods are applicable to many other objective functions. Fourthly, our framework is capable to solve not only the valve location problem, but also a reverse one, where it is required to find the minimum number of shutoff valves together with their location while maintaining some admissible maximum environmental damage. Finally, our approach is applicable to pipe networks transporting any hazardous liquids.

Paper organization. In Section 2 we formally define the problem and discuss the methods for quantification of environmental damages. In Section 3 we start with the simplest possible pipe network where the valves should be installed along a linear pipe segment. For this basic problem we construct two algorithms: (i) dynamic programming algorithm, and (ii) binary search "guessing" algorithm. Depending 
on the instance of the problem, we choose the algorithm with better performance in terms of running time. Using the results for linear segments, in Section 4 we design yet another dynamic programming algorithm for an optimal allocation of valves among the linear segments of a general pipe network. In Section 5, we compare the valve location returned by our framework with the current solution to the real-life pipeline (a fragment of ESPO).

\section{Problem definition for linear pipeline segments}

Consider a linear segment of a pipe network, i.e., a part of the network where the pipeline does not split. A linear pipeline segment consists of a number of discrete pipes. Let $n+1$ be the number of such pipes. We assume that the set of pipe endpoints is given by their (without loss of generality, integer) coordinates in $\mathbb{R}^{2}$, where $y$-coordinate corresponds to the point altitude (the vertical elevation of the point above the sea level), and $x$-coordinate corresponds to the horizontal projection of the point when the pipeline is "stretched" on a plane. Let $\left\{\left(x_{0}, y_{0}\right)\left(x_{1}, y_{1}\right), \ldots,\left(x_{n+1}, y_{n+1}\right)\right\}$ be the set of pipe endpoints such that $0=x_{0}<x_{1}<\ldots<x_{n+1}=T$, where $\left(x_{0}, y_{0}\right)$ and $\left(x_{n+1}, y_{n+1}\right)$ are the endpoints of the pipeline segment. We denote $X=\left\{0, x_{1}, x_{2}, \ldots, x_{n}, T\right\}$.

Further we assume that the entire linear pipeline segment is a continuous piecewise linear function in $\mathbb{R}^{2}$ with breakpoints in $X$. For an illustration see Figure 1, where 47,5 kilometers long linear segment of the real-life pipeline (ESPO) is represented. The landscape is complex (with many rivers and hills). Axis $y$ is measured in hundreds meters and axis $x$ is measured in kilometers. Here, the pipeline segment consists of 97 pipes, where each of the pipes is about 500 meters long.

Technologically, a shutoff valve cannot be placed in an arbitrary point of the pipeline but only between two consecutive pipes. Since the shutoff valves are very expensive, there is only a limited amount of these devices. We let $m$ be the number of valves and we assume 
that at points 0 and $T$ the valves are installed by default. In our test example, three valves must be installed along the pipeline.

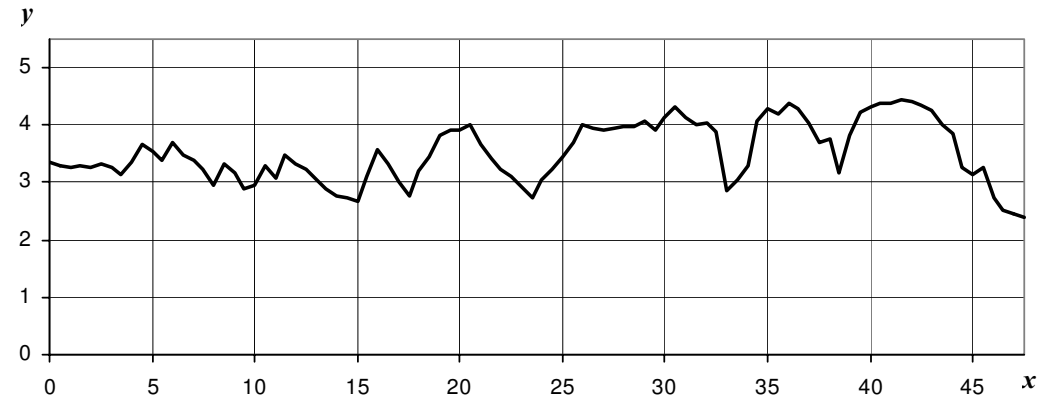

Fig. 1. A linear segment of a pipeline.

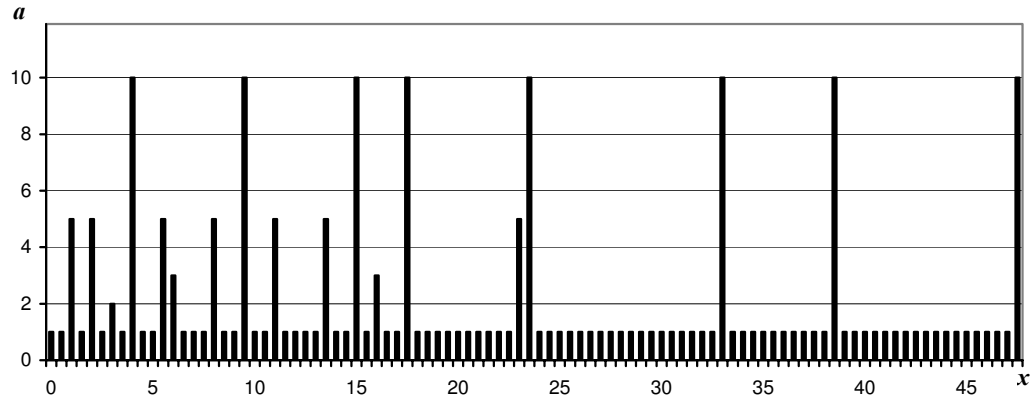

Fig. 2. Weights of ecologic damage.

To compute potential ecologic damages, we use the following approach. First, for each pipe $k \in\{1,2, \ldots, n+1\}$, we define a positive integer weight $a_{k}$ of ecologic damage dependent on the landscape around pipe $k$. We determine these weights as follows: the minimum weight is always 1 ; if a pipe crosses a road or railway, the weight takes value 3 ; if a pipe crosses a water stream, it becomes 5; and finally, for pipes crossing rivers the weights equal 10. For our test case, the weights are presented in Figure 2. More accurate and more complex methods determining the ecologic damage weights can be 
found, e.g., in the methodology by the Russian Ministry of Energy (1995).

Next, for each pipe $k$ and each pair $\left(x_{i}, x_{j}\right) \in X^{2}$ such that $x_{i}<x_{k} \leq x_{j}$, we define $V_{k}\left(x_{i}, x_{j}\right)$ being the maximum volume of potentially leaked oil on valve-free interval $\left(x_{i}, x_{j}\right)$, given that the pipeline is damaged in pipe $k$. Then, for each interval $\left[x_{i}, x_{j}\right]$, the maximal potential damage equals

$$
R\left(x_{i}, x_{j}\right)=\rho \phi \max _{k: x_{i}<x_{k} \leq x_{j}} a_{k} V_{k}\left(x_{i}, x_{j}\right)
$$

where $\rho=0,86 t / \mathrm{m}^{3}$ is the physical density of oil, and $\phi=2742,80$ Russian Rubles is the monetary equivalent of the minimum environmental damaged caused by one ton of oil leaked from a long oil pipeline expressed in prices of year 2000; see the report of the State Enterprise NTC for Industial Safety (2000).

Now, a feasible solution $S=\left\{x_{1}^{\prime}, x_{2}^{\prime}, \ldots, x_{m}^{\prime}\right\}$ to the valve location problem is an $m$-elementary subset of points from $X$ where $m$ valves will be installed. Without loss of generality, we assume $0=x_{0}^{\prime}<$ $x_{1}^{\prime}<x_{2}^{\prime}<\ldots<x_{m}^{\prime}<x_{m+1}^{\prime}=T$. The problem is to find a feasible solution $S=\left\{x_{1}^{\prime}, x_{2}^{\prime}, \ldots, x_{m}^{\prime}\right\}$ that minimizes $\max _{0 \leq i \leq m} R\left(x_{i}^{\prime}, x_{i+1}^{\prime}\right)$.

Notice that the input of the problem is very succinct and consists of a set of $n+1$ breakpoints and coefficients $a_{k}, k \in\{1,2, \ldots, n+1\}$. Thus, the total encoding length of the input is $O\left(n \log T+n \log y_{\max }+\right.$ $\left.n \log a_{\max }\right)$ or roughly $O(n)$ if we disregard the encoding length of the numbers.

Values $R\left(x_{i}, x_{j}\right), x_{i}, x_{j} \in X$, are the subjects to additional computations. For any interval $\left[x_{i}, x_{j}\right]$, the corresponding value $R\left(x_{i}, x_{j}\right)$ can be computed in time $O\left(n^{2}\right)$ using the following simple algorithm. First, for all $k$ such that $x_{i}<x_{k} \leq x_{j}$, the algorithm computes values $V_{k}\left(x_{i}, x_{j}\right)$. This can be done by taking the total length of elevating pipes to the left and to the right of (damaged) pipe $k$ within interval $\left[x_{i}, x_{j}\right]$, and multiplying the result by the constant inner area of the pipeline cut. Then, the value $R\left(x_{i}, x_{j}\right)$ is obtained directly from Equation (1). 


\section{Optimal valve location on a linear segment}

Dynamic programming. In this section we design and compare two algorithms computing an optimal valve location for a linear segment of a pipeline. The first algorithm is the textbook dynamic programming algorithm. Consider a point $x_{j} \in X$ of the pipeline. Assume that we placed the $\ell^{\text {th }}$ valve $(1 \leq \ell \leq m)$ at point $x_{j} \in X$. Let $F(\ell, j)$ be the maximum environmental damaged on interval $\left[0, x_{j}\right]$ under assumption that the first $\ell-1$ valves were located optimally to minimize this maximum damage. Define $F(0, i)=R\left(0, x_{i}\right)$ for all $x_{i} \in X$. Then, we have the following recurrent equation:

$$
F(\ell, j)=\min _{0 \leq i<j} \max \left\{F(\ell-1, i), R\left(x_{i}, x_{j}\right)\right\}
$$

and the optimal objective value equals

$$
O P T=\min _{1 \leq j \leq n} F(m, j) .
$$

Now, the optimal valve location can be derived simply by taking the arguments of the minimums in Equations (2) and (3).

The algorithm above finds a solution to the problem in time $O\left(n^{4}\right)$. This running time is unavoidable since we have to evaluate values $R\left(x_{i}, x_{j}\right)$ for $\Omega\left(n^{2}\right)$ pairs $\left(x_{i}, x_{j}\right)$. In our implementations, we compute all values $R\left(x_{i}, x_{j}\right)$ in the preprocessing. Then, the dynamic programming itself takes only $O\left(m n^{2}\right)$ time which is negligible compared to the preprocessing. The high time complexity of the dynamic programming algorithm is compensated by its tolerance to many other optimization criteria. For instance, substituting maximization in Equation (2) by summation, we can easily adjust the dynamic programming to the average environmental damage minimization. Then, introducing the probabilities of pipe failures, we can construct a dynamic programming algorithm solving the expected environmental damage minimization problem.

Binary search "guessing" algorithm. The second algorithm is based on a totally different approach using specific of the min-max objective. On the upper level, we make a binary search for the (without 
loss of generality, integral) minimum maximal environmental damage. One can see this as a "guessing" on the optimal value of the objective function. In such a binary search, the upper bound for the maximum damage $d$ is clearly $R(0, T)$, and the lower bound is 0 . We initialize the binary search setting $a:=0, b:=R(0, T), d=$ $\lfloor(a+b) / 2\rfloor$. At each step of the upper level binary search, given a triple $(a, b, d)$, we simply test whether exists a feasible solution to the problem with maximum damage at most $d$ or not. If there is a solution with maximum damage at most $d$ we set $a:=a, b:=d, d=$ $\lfloor(a+b) / 2\rfloor$, otherwise we set $a:=d, b:=b, d=\lfloor(a+b) / 2\rfloor$. We stop the binary search when $a=b=d$.

For the feasibility test, we consecutively locate the shutoff valves on the linear pipeline segment using yet another (lower level) binary search. Suppose we placed already $\ell-1$ valves $(1 \leq \ell \leq m)$, and the last valve is placed at $i_{\ell-1}$ assuming that $i_{0}=0$. If $i_{\ell-1}<n+1$ we continue, otherwise we stop because we already found a feasible valve location with maximum damage at most $d$. Consider valve $\ell$. We set $s:=i(\ell-1), t:=n+1$ and we let $i=\lfloor(s+t) / 2\rfloor$. If $R\left(x_{\ell-1}^{\prime}, x_{i}\right) \leq d$, we define $s:=i, t:=t, i=\lfloor(s+t) / 2\rfloor$; otherwise $s:=s, t:=i, i=\lfloor(s+t) / 2\rfloor$. Stop when $s=t=i$ and locate the $\ell^{\text {th }}$ valve at $i$, i.e. $x_{\ell}^{\prime}=x_{i}$. If $R\left(x_{m}^{\prime}, T\right)>d$ then stop: there is no feasible solution maintaining the maximum damage $d$.

Notice that the second (binary search "guessing") algorithm does not require evaluation of all values $R\left(x_{i}, x_{j}\right),\left(x_{i}, x_{j}\right) \in X^{2}$. This allows us to derive an optimal valve location in time $O\left(m n^{2} \log ^{2} n\right)$, which is factor of $O\left(n^{2} /\left(m \log ^{2} n\right)\right)$ better than the performance of the dynamic programming algorithm. Applied to the test instance above with $n=97, m=3$ and the proper constants in the big $O$, we observe that the second algorithm is about 50 times faster than the dynamic programming. Another advantage of the binary search "guessing" algorithm is that it solves not only the optimal valve location problem but also the reverse problem of finding the minimum number of valves while maintaining some admissible level of maximum environmental damage. Moreover, since the maximum admissible damage in the reverse problem is given explicitly in the problem input, the upper level binary search is obsolete. Therefore, 
an optimal solution to the reverse problem can be obtained even in $O(\log n)$ times faster.

We omit the mathematical proofs of correctness of the constructed algorithms. Restoration of these proofs is not difficult. For a typical example of such a proof see, e.g., the textbook on combinatorial optimization by Papadimitriou and Steiglitz (1982).

\section{Optimal valve location on a general pipe network}

In the previous section we show that the valve location problem and the reverse problem of finding the minimum number of valves, maintaining a certain level of maximum environmental damage, can be solved efficiently for linear segments of a pipe network. In reality, however, the pipe networks are quite complicated having many branches and split points; for an illustration see Figure "Oil pipelines in Europe" in Wikipedia (2007).

Fortunately, all split points of the long oil pipelines are the pump stations or tanks where the valves must be installed by default, see, e.g., Electronic Code of Federal Regulations (2007). This significantly simplifies the valve location problem. In fact, the only question remains is how to optimally allocate the valves among the linear segments of the network? More explicitly, given a total number $M$ of valves to be installed on a set $E$ of linear segments of a general pipe network, one have to assign numbers of valves $m_{e}$ to the linear segments $e \in E$ such that $\sum_{e \in E} m_{e} \leq M$ and the maximum environmental damage over all linear segments is minimized. The following dynamic program solves this problem to optimality.

Assume all linear segments of the pipe network are numbered, $E=\{1,2, \ldots, Q\}$. Let $F_{q}(m)$ be the maximum damage on linear segment $q$ when $m$ valves are optimally located along this segment, computed as described in Section 3. Let $S(q, m), 1 \leq q \leq Q, 1 \leq$ $m \leq M$, be the maximum damage over linear segments $\{1,2, \ldots, q\}$ when $m$ valves are optimally located on these segments. For completeness, we also define $S(0, m)=0$ for all $1 \leq m \leq M$. Then, for 
all $1 \leq q \leq Q$, we have the following recurrent equation:

$$
S(q, m)=\min _{0 \leq m^{\prime} \leq m} \max \left\{S\left(q-1, m^{\prime}\right), F_{q}\left(m-m^{\prime}\right)\right\},
$$

and the optimal objective value equals

$$
O P T=S(Q, M)
$$

Again, the optimal allocation of valves among the linear segments can be derived by taking the arguments in the minimums in Equations (4) and (5).

It is also straightforward to extend binary search "guessing" algorithm to solve the problem (and the reverse one) for a general network with shutoff valves in split points.

\section{Test case study}

Let us remind that in the test instance presented in Section 2, we have to install three valves. In Figure 3(a) we present the solution computed by methodology from the State Scientific Research Institute of Oil Transportation (1972), currently used in Russian pipeline construction. In Figure 3(b) we introduce the optimal solution computed by our framework.

It is intuitively clear why the shutoff valves in our solution are shifted to the left: on the first 25 kilometers of the pipeline there are more streams and rivers than on the last 20 kilometers. Thus, potential ecologic damage in the beginning of the pipeline is much higher than at the end. Amazingly, not only the valve location patterns in these two solutions are very much different, but also the resulting maximum environmental damages: in the first solution the maximum damage is 178,1 billion Russian Rubles when in the second one the optimum equals only 112 billion. Therefore, when locating the valves as suggested by our framework, the potential ecologic damage can be reduced by $37 \%$. This brings us to the conclusion that the valve location solutions computed by our framework can significantly improve ecologic safety of the oil pipelines. 


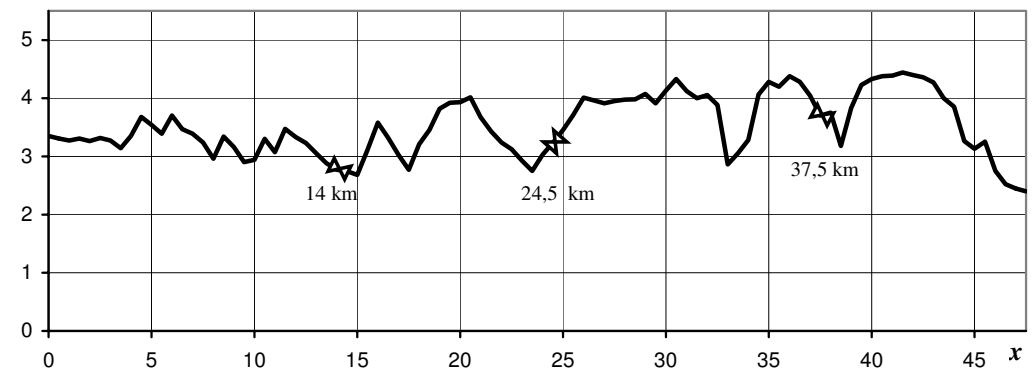

(a) Current solution.

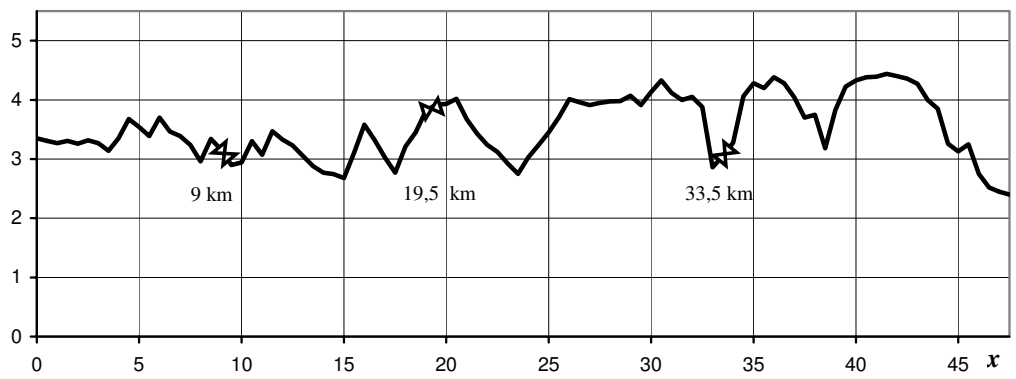

(b) Optimal valve location.

Fig. 3. Solutions for the test case.

\section{References}

Electronic Code of Federal Regulations (e-CFR). 2007. Title 49 - Transportation, part 195 - Transportation of Hazardous Liquids by Pipeline, $§ 195.260$ - Valves: Location. Retrieved February 20, 2007.

http://www.gpoaccess.gov/cfr/index.html

Federal Register. 2002. Pipeline Safety: Recommendations To Change Hazardous Liquid Pipeline Safety Standards. Federal Register 67 (173), September 6, 2002, 56970-56976.

Greenpeace. 2005. Decision on "Eastern Siberia - Pacific Ocean" Pipeline Caused New Protests of Ecologists. Retrieved February 20, 2007.

http://www.greenpeace.org/russia/en/news/decision-on-eastern-siberia.html

Papadimitriou C. H. and K. Steiglitz. 1982. Combinatorial Optimization: Algorithms and Complexity. Prentice Hall: Englewood Cliffs, N.J. 
The Ministry of Energy (MinTopEnergo), Moscow, Russia. 1995. A method for computing the accidental environmental damage in the long oil pipelines. TransPress, Moscow, Russia, 1996. Approved by the Ministry of Energy, Russia, November 01, 1995. (in Russian).

The State Enterprise NTC for Industial Safety, Moscow, Russia. 2000. A methodology for the risks estimations on the long oil pipelines. GosGorTechNadzor, Moscow, Russia. (In Russian).

The State Scientific Research Institute of Oil Transportation (VNIISPTNEFT), Ufa, USSR. 1972. A method for an optimal location of shutoff valves in the long oil product pipelines. Approved by the Ministry of Oil Industry, USSR, February 02, 1972. (In Russian).

Wikipedia, the free enciclopedia. 2007. Druzhba pipeline. Retrieved March 01, 2007, http://en.wikipedia.org/wiki/Druzhba_pipeline.html 